\title{
Analisis Insektisida Organoklorin Pada Bulu Walet Sarang Putih (Collocalia fuciphaga Thunberg)
}

\section{The Analysis of organochlorine insecticide in Collocalia fuciphaga Thunderberg Feathers}

\author{
Oktaf Laudensius ${ }^{1 *)}$, Pramana Yuda ${ }^{2)}$, dan Kianto Atmodjo ${ }^{2 *}$ \\ ${ }^{I}$ SLTP/SLTA Xaverius I Jl. Abdurahman Saleh19 Jambi, Email : oktafds@yahoo.com \\ ${ }^{2}$ Fakultas Biologi Universitas Atma Jaya Yogyakarta
}

\begin{abstract}
The objectives of this study are to find out the kind and quantitative of organochlorine insecticide in swallow (Collocalia fuciphaga Thunderberg) feathers. The samples were plumae of wing and tail feathers from the birds were catched in Siluk, Gunungkidul and Sedayu, Bantul on August and September 2002 The organochlorine insecticide compound were analysed by gas chromatography-electronic catcher detector. The analysis result found out the organochlorine insecticide in swallow feathers, were heptachlor (0-5855 ppm) and pp-DDD (0-0929 ppm).
\end{abstract}

Keywords : plumae, organochlorine, chromatography

Diterima: 12 Desember 2002, disetujui 20 April 2003

\section{Pendahuluan}

Jumlah pestisida terdaftar dan diizinkan oleh Departemen Pertanian menurut Anonim (2001a) sebesar 678 merk dagang. Menurut Anonim (2001b) di Propinsi Daerah Istimewa Yogyakarta terdapat 20 jenis merek dagang insektisida tingkat kios, 19 jenis merek dagang insektisida tingkat lapangan dan 9 jenis merek dagang insektisida tingkat pengguna dari berbagai golongan. Berdasarkan data tersebut, heptaklor dan DDT sudah tidak beredar di kalangan petani. Namun, survei lapangan menunjukkan bahwa petani di Kabupaten Bantul masih menggunakan organoklorin (DDT) yang dicampur dengan insektisida golongan lain sehingga memiliki daya bunuh yang cepat dan tinggi.

Insektisida yang beredar di Propinsi Daerah Istimewa Yogyakarta memiliki formulasi, cara kerja dan susunan kimia yang bervariasi. Insektisida pada tingkat petani, menggunakan 5 jenis insektisida yang memiliki formulasi berupa cairan dan digunakan dengan cara penyemprotan. Kelima jenis insektisida tersebut adalah Decis 25 EC, Fastac 15 EC, Matador 25 EC, Marshall 200 EC dan Rubigan 200 EC. Cara kerja insektisida tersebut menurut Sudarmo (1992) adalah insektisida kontak, lambung/perut dan pernafasan. Hal tersebut berarti bahwa insektisida tersebut mengenai bagian tubuh, masuk melalui mulut dan masuk melalui pernafasan organisme sasaran. Dengan demikian, kemungkinan organisme non target dapat terkena insektisida tersebut. Contoh organisme non target adalah burung gereja (Chao dan Mei, 2002) dan walet (Drooge, 1998).

Hasil penelitian Kuncoro et.al., (2002) menunjukkan bahwa walet sarang putih di DIY mengandung insektisida organofosfat, yaitu golongan diazinon. Jumlah diazinon pada bulu sebesar 0,159 ppm, saluran pernafasan sebesar $0,150 \mathrm{ppm}$ dan saluran serta kelenjar pencernaan sebesar $0,018 \mathrm{ppm}$. Hasil penelitian tersebut menunjukkan bahwa kandungan insektisida diazinon pada bulu lebih besar dibandingkan saluran pernapasan dan kelenjar 
serta saluran pencernaan. Oleh karena itu, bulu dapat dijadikan organ sampel untuk analisis insektisida tanpa harus membunuh organismenya.

Penelitian ini membuktikan bahwa burung walet sarang putih adanya insktisida organoklorin pada burung walet sarang putih.

\section{Metode Penelitian}

\section{Pengambilan sampel}

Burung walet sebanyak 10 ekor ditangkap menggunakan jala di sawah pada sore hari. Penangkapan dilakukan pada bulan Agustus 2002 sebagai sampel 1, 2, 3, 4 dan 5 dan bulan September 2002 sebagai sampel 6, 7, 8, 9 dan 10. Lokasi penangkapan berada di Siluk Kabupaten Gunungkidul dan Sedayu.Kabupaten Bantul. Setiap Burung walet diambil bulu plumae (Contour feathers) pada sayap kanan dan kiri serta ekor masingmasing sebanyak 1 helai. Bulu ditimbang dan diperoleh berat rata-rata 0.13818 gram.

\section{Persiapan Sampel}

Persiapan dilakukan pada bulan Oktober 2002 di Laboratorium Balai Penyelidikan dan Pengujian Verteriner Wilayah IV Yogyakarta. Bulu dipotong kecil-kecil menggunakan gunting, direndam dengan $10 \mathrm{ml}$ Petroleumbenzine selama 1 malam dalam botol teflon tertutup. Setelah itu, bulu digerus menggunakan cawan porselin sampai halus.lalu dimasukkan kembali ke botol lain berbeda dan direndam lagi. Cawan dibersihkan dengan 10 ml Petroleumbenzine dan dimasukkan ke dalam botol yang berisi gerusan bulu. Botol didiamkan selama 1 malam. Rendaman disaring menggunakan kertas whatman no 40. Hasil saringan ditampung di botol evaporator $50 \mathrm{ml}$, lalu dievaporasi sampai tinggal $\pm 2 \mathrm{ml}$ menggunakan Rotary Vacuum Evaporator. Residu hasil evaporasi dilarutkan dengan $10 \mathrm{ml}$ heksana dan diultrasonik untuk melarutkan residu yang menempel di dinding kaca. Residu dipindahkan ke tabung reaksi $5 \mathrm{ml}$.

Residu dimurnikan dengan cara dialirkan dalam kolom pipet yang glass wool pada mulut pipet, natrium sulfat dengan panjang $1 \mathrm{~cm}$, florisil dengan panjang $10 \mathrm{~cm}$ (kedua senyawa ini terlebih dahulu diaktivasi selama 24 jam pada oven $110^{\circ} \mathrm{C}$ ). Kemudian dielusi dengan dietil eter $6 \%$ dalam petroleum eter dan ditampung. Setelah itu dielusi lagi dengan dietil eter $15 \%$ dalam petroleum eter dan ditampung, kemudian hasil tampungan dicampur sebagai hasil elusi. Organoklorin akan terelusi $1 / 3$ dalam dietil eter $6 \%$ dan $2 / 3$ dalam dietil eter $15 \%$. Hasil elusi ditampung dalam botol evaporator $10 \mathrm{ml}$. Hasil elusi dievaporasi menggunakan Rotary Vacum Evaporator (merek Wheaton Eye LA ${ }^{@}$ seri NE-1) sampai hampir kering. Botol evaporasi diultrasonik ( merek Fisher Scientific seri B5200E1) sambil dibilas dan dialiri dengan heksana sebanyak $2 \mathrm{ml}$ yang bertujuan untuk mengambil residu dan ditampung dalam tabung reaksi $5 \mathrm{ml}$ yang sama. Tabung reaksi $5 \mathrm{ml}$ didiamkan semalam. Residu dikeringkan dalam oven $40^{\circ} \mathrm{C}$ sampai hampir kering. Kemudian residu ditambahkan aldrin 5 mikro liter yang dilarutkan dengan $0,5 \mathrm{ml}$ heksana sebagai standar internal. Diharapkan konsentrasi aldrin pada sampel sebesar 0,1884 ppm. Standar internal dibuat sebagai pembanding antara waktu retensi aldrin dalam larutan standar dengan waktu retensi aldrin dalam sampel sehingga diketahui pergeseran waktu retensinya. Setelah itu, residu siap diinjeksikan ke dalam Kromatografi gas.

\section{Analisis Sampel}

Larutan sampel dan standar (disiapkan sebanyak delapan senyawa yaitu $\propto$ BHC 0,25 ppm, heptaklor $0,5 \mathrm{ppm}$, dieldrin $0,25 \mathrm{ppm}$, pp-DDE 0,5 ppm, op-DDT 1 ppm, pp-DDD 0,5 ppm dan pp-DDT' $0,5 \mathrm{ppm}$ ) dimasukkan secara bergantian ke alat kromatografi gas detektor penangkap elektron merek Shimadzu seri GC-14.B.menggunakan alat injector $1 \mathrm{ml}$. Kromatografi gas yang dipakai untuk menginjeksi standar dan sampel dengan kondisi sebagai berikut :

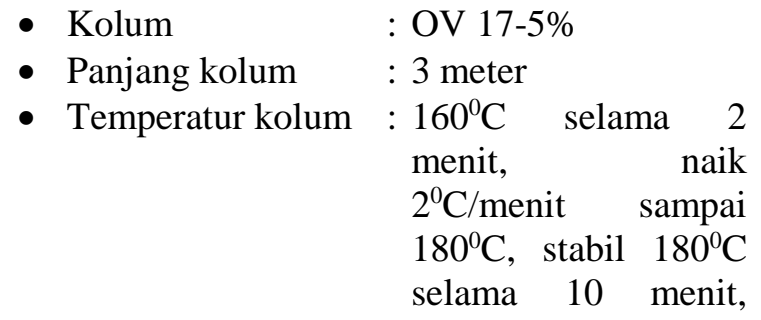




$$
\begin{array}{lr}
\text { suhu dinaikkan } \\
1{ }^{\circ} \mathrm{C} / \text { menit } & \text { sampai } \\
195^{\circ} \mathrm{C} \text {, stabil selama } \\
10 \text { menit. Suhu } \\
\text { pencucian } 240^{\circ} \mathrm{C} \\
\text { selama } 2 \text { menit. }
\end{array}
$$

- Temperatur detektor : $250^{\circ} \mathrm{C}$

- Temperatur injektor : $240^{\circ} \mathrm{C}$

- Detektor : Electron Capture

- Gas nitrogen UHP : 99,999\% kecepatan alir $30 \mathrm{ml} /$ menit.

Setiap pergantian sampel, injektor dibersihkan dengan heksana agar sampel berikutnya tidak terkontaminasi oleh sampel yang telah diinjeksikan.. Kadar organoklorin berdasarkan pada perhitungan Nur et.al., (1992).

\section{Hasil dan Pembahasan}

Hasil analisa kualitatif organoklorin pada burung walet putih menunjukkan tidak semua sample mengandung insektisida yang dimaksud, namun hanya 4 sampel bulu yang positif mengandung organoklorin (Tabel 1). Ini berarti burung walet sarang putih terbukti tercemar juga oleh organoklorin, selain tercemar oleh organofosfat (Kuncoro et al., 2001). Selain itu juga membuktikan bahwa sebagai organisme non target, burung ini terancam terkena dampak penggunaan isnektisida bagi dunia pertanian (Heong and Escalada, 1997) baik secara langsung maupun tidak langsung dan mungkin dapat juga digunakan sebagai bioindikator pencemaran lingkungan (Drooge, 1998; Chao and Mei. 2002).

Berdasarkan analisa kuantitatif (tabel 2) kandungan organoklorin pada sampel menunjukkan bahwa 10\% sampel mengandung heptaklor dengan kisaran 0 sampai 0,5855 ppm. Selain itu, $40 \%$ sampel mengandung $p p$ DDD. antara 0 sampai 0,0929 ppm.Sampel bulu yang dianalisis, sebagian menunjukkan hanya mengandung heptaklor dan pp-DDD saja, sampel yang lain ada yang mengandung keduanya. Kamrin (1997) menjelaskan bahwa heptaklor dan metabolitnya yaitu epoxide heptaklor terakumulasi dalam jaringan lemak pada ikan dan burung, bahkan dapat ditemukan pula pada hati, otot dan telur burung. Sedangkan adanya $p p-D D D$ mungkin merupakan akumulasi lama, karena Menurut Connell and Miller (1995), pp-DDD adalah hasil degradasi yang diturunkan dari dehidroklorinasi biologis dan deklorinasi reduktif DDT, dan senyawa $p p$-DDD bersifat stabil dan aktif secara biologis. Atau bisa juga DDT yang terlarang itu masih digunakan.

Adanya variasi jenis dan kuantitas organoklorin pada bulu walet sarang putih disebabkan dua faktor yaitu daya jelajah dan umur (Mardiastuti et.al., 1998). Daya jelajah walet sarang putih berkisar antara 25 sampai 40 $\mathrm{km}$. Dengan demikian, semakin jauh daerah jelajah walet sarang putih maka kemungkinan mengalami kontak dengan insektisida semakin besar. Adapun dari segi umur, rata-rata ketahanan hidup walet sarang putih adalah 14 tahun, sedangkan waktu paro organoklorin dalam jaringan hewan antara 3 - 5 tahun (Hassal, 1990 ; Connell and Miller, 1995). Dengan demikian, semakin besar usia walet sarang putih maka kemungkinan akumulasi insektisida organoklorin dalam tubuhnya semakin tinggi.

Insektisida masuk ke tubuh walet sarang putih melalui rantai makanan. Hal ini dijelaskan Mardiastuti et.al., (1998) bahwa walet sarang putih menduduki tingkat trofik ketiga yaitu memangsa serangga kecil dari ordo Hymenoptera, Diptera, Homoptera dan Coleoptera yang tertangkap ketika terbang. Serangga yang menjadi makanan utama burung walet sarang putih menurut Sudarmo (1992) dan Anonim (2001a), merupakan target insektisida organofosfat, organoklorin, karbamat dan golongan lain. Connell (1995) menegaskan bahwa residu insektisida organoklorin yaitu DDT dan turunannya yaitu $p p$-DDD mengalami kenaikan dalam tingkatan trofik dan terakumulasi dalam rantai makanan.

Selain melalui rantai makanan, insektisida di udara dapat menempel pada bulu burung walet sarang putih dan bahkan terhirup oleh walet sarang putih saat melakukan pernafasan (Drooge,1998). Kondisi ini mirip keberadaan logam berat pada bulu burung gereja (Chao and Mei, 2002), burung Accipiter gentilis (Furness and Greenwood, 1993). 
Penelitian tersebut, mendukung kemungkinan adanya kontak langsung insektisida organoklorin atau golongan lain di bulu.

\section{Kesimpulan dan Saran}

Kesimpulan penelitian ini adalah insektisida organoklorin berupa heptaklor dan $p p$-DDD terbukti terdapat pada bulu walet sarang putih. Kandungan heptaklor pada bulu walet sarang putih berkisar maksimum 0,5855 ppm dan $p p$-DDD maksimum 0,0929 ppm.

Berdasarkan penelitian ini disarankan untuk meneliti kandungan insektisida pada serangga terbang yang merupakan hama bagi tanaman budidaya dan juga sebagai makanan burung walet.

\section{Daftar Pustaka}

Anonim. 1997. Metode Pengujian Residu Pertanian Dalam Hasil Pertanian. Komisi Pestisida, Departemen Pertanian. Jakarta.

Anonim. 2000. Sekitar 900 Senyawa Kimia Dapat Menimbulkan Kanker. Kompas. Selasa. 31 Oktober 2000.

Anonim. 2001a. Pestisida Untuk Pertanian dan Kehutanan. Direktorat Pupuk dan Pestisida, Direktorat Jendral Bina Sarana Pertanian, Departemen Pertanian. Jakarta.

Anonim. 2001b. Laporan Pengawasan Pestisida : Proyek Pengembangan Sumberdaya Pertanian Tanaman Pangan dan Hortikultura. Dinas Pertanian Propinsi Daerah Istimewa Yogyakarta Sub Dinas Pertanian Tanaman Pangan dan Hortikultural. Yogyakarta.

Anonim. 2001c. Produk Pertanian Ditolak Akibat Residu Pestisida : Sumbar Bebas Pestisida. Kompas. Rabu. 22 Agustus 2001.

Anonim. 2001d. Bantul Kembangkan Varietas Padi Tahan Hama. Kompas.Jumat.24 Agustus 2001.
Chao.P. and Z. G. Mei. 2002. The Tree Sparrow Passer montanus as an Indicator Species for Monitoring Urban Environments In Abstract Volume, $23^{\text {rd }}$ International Ornitological Congress. Beijing. China.

Connell. Des.W.1995. Bioakumulasi Senyawaan Xenobiotik. Terjemahan. UIPress. Jakarta.

Connell.D.W and G.J. Miller. 1995. Kimia dan Ekotoksikologi Pencemaran. Terjemahan. Penerbitan Universitas Indonesia. Jakarta.

Drooge,B.L.van. 1998. Organochlorine residues and fatty acid compositions in the livers of Diurnal Raptors From The Iberian Peninsula. Final Project. Van Hall Institute, Environmental Science Leeuwareden, The Netherlands.

Furness.R.W. and J.J.D. Greenwood. 1993. Birds as Monitors of Environmental Change. Chapman and Hall. Australia.

Hassall.K.A. 1990. The Biochemistry and Uses of Pesticides. McMillan pres.LTD. London.

Heong, K.L and M.M. Escalada. 1997. A comparative analysis of pest management practice of rice farmes in asia in Pest Management of Rice Farmes in Asia. International Rice Research Institute. Manila, Phillippines.

Kamrin. M.A. 1997. Pesticides Profiles : Toxicity, Environmental Impact and Fate. Lewis Publisher. Boca Raton. New York.

Khopkar. S. M. 1990. Konsep Dasar Kimia Analitik.Terjemahan. Penerbit Universitas Indonesia Press. Jakarta.

King, B., M. Woodcock and E.C.Dickinson. 1995. Collins Field Guide : Birds of South-East Asia. Harper Collins Publisher. London. Glasgow. Sydney. Auckland. Toronto. 
Kusno. S. Ir. 1994. Pencegahan Pencemaran Pupuk dan Pestisida. Penebar Swadaya. Jakarta.

Kuncara. J.H., Y. Aida dan P. Yuda. 2002. Akumulasi Organofosfat pada Walet Sarang Putih (Collocalia fuciphaga Thunberg). Biota.Vol.VII(2):89.

Martini.F.H. and E.F. Bartholomew. 1998. Essentials of Anatomy and Physiology.Prentice-Hall International, Inc. New York.

Sudarmo.D., 1992. Pestisida Untuk Tanaman. Penerbit Kanisius. Yogyakarta.

Peterle. T. J. 1991. Wildlife Toxicology. Van Nonstrand Reinhold. New York.

Mardiastuti. A., Mulyani.Y.A. Sugarjito. J., Ginoga. LN. Maryanto. I., Nugraha. A. dan Ismail, 1998, Tehnik Pengusahaan Walet Rumah, Pemanenan Sarang dan Penanganan Pasca Panen. Laporan Riset. Unggulan Terpadu IV Bidang Tehnologi Perlindungan Lingkungan (1995-1997). Kantor Menteri Negara Riset dan Tehnologi. Dewan Riset nasional. Bogor.

Nur.M.N., H. Adijuwana dan Kosasih. 1992. Teknik Laboratorium: Petunjuk Laboratorium. Departemen Pendidikan dan Kebudayaan, Dirjen Pendidikan Tinggi, PAU Ilmu Hayati, Institut Pertanian Bogor. Bogor.

Sawyer. L.D., B.M. McMahon., W.H. Newsome and G.A. Parker. 1990. Pesticides and Industrial Chemical Residues. Association of Official Analytical Chemists, 12 ed. Washington DC.

Untung. K., 1993. Pengantar Pengelolaan Hama Terpadu. Gadjah Mada University Press. Yogyakarta

Tabel 1.Analisis kualitatif insektisida organoklorin pada bulu walet sarang putih.

\begin{tabular}{cc}
\hline Sampel & Insektisida Organoklorin \\
\hline \hline 1 & - \\
2 & - \\
3 & + \\
4 & - \\
5 & + \\
6 & + \\
7 & - \\
8 & - \\
9 & - \\
10 & + \\
\hline
\end{tabular}

Keterangan : $\quad+=$ ada; $\quad-=$ tidak ada 
Tabel 2. Kadar insektisida organoklorin (ppm) pada bulu walet sarang putih .

\begin{tabular}{clllllll}
\hline \multirow{2}{*}{ Sampel } & \multicolumn{6}{c}{ Kandungan Insektisida Organoklorin (ppm) } \\
\cline { 2 - 7 } & \multirow{2}{*}{$\propto$ BHC } & Heptaklor & Dieldrin & $\boldsymbol{p p}$-DDE & $\boldsymbol{o p}$-DDT & $\boldsymbol{p p}$-DDD & \multicolumn{1}{c}{$\boldsymbol{p} \boldsymbol{p}$-DDT ${ }^{\prime}$} \\
\hline \hline 1 & 0 & 0 & 0 & 0 & 0 & 0 & 0 \\
2 & 0 & 0 & 0 & 0 & 0 & 0 & 0 \\
3 & 0 & 0.5855 & 0 & 0 & 0 & 0.042 & 0 \\
4 & 0 & 0 & 0 & 0 & 0 & 0 & 0 \\
5 & 0 & 0 & 0 & 0 & 0 & 0.0692 & 0 \\
6 & 0 & 0 & 0 & 0 & 0 & 0.0929 & 0 \\
7 & 0 & 0 & 0 & 0 & 0 & 0 & 0 \\
8 & 0 & 0 & 0 & 0 & 0 & 0 & 0 \\
9 & 0 & 0 & 0 & 0 & 0 & 0 & 0 \\
10 & 0 & 0 & 0 & 0 & 0 & 0.0174 & 0 \\
\hline
\end{tabular}

